\title{
Experiment and numerical simulation of a valveless piezoelectric micropump applying Coanda effect
}

\author{
Xiuhua He ${ }^{1, a}$, Xitong Zhang ${ }^{1}$, Song Yang ${ }^{2}$, Jiawei Zhu ${ }^{1}$ and Jie Yan ${ }^{1}$ \\ 1 School of Energy and Power Engineering, Jiangsu University, 301 Xuefu Road, Zhenjiang 212013, P.R. China \\ 2 Research Center of Fluid Machinery Engineering and Technology, Jiangsu University, 301 Xuefu Road, \\ Zhenjiang 212013, P.R. China
}

Received 30 November 2014, Accepted 1 May 2015

\begin{abstract}
To improve the flowrate and the volumetric efficiency of the valveless piezoelectric micropump, a valveless piezoelectric micropump based on Coanda effect was designed and fabricated by Polymethylmethacrylate (PMMA). Its performance including the flowrate and the maximum back pressure, optimum operating condition, working principle as well as the diffuser angle were discussed. An experiment was carried out to obtain the performance of the micropump and search for the optimum operating condition. The high-speed photograph was utilized to obtain the instantaneous volume changing rate of the chamber in the experiment. A numerical simulation was done to obtain the flow field of the micropump to specialize its working principle. To discuss the effects of the diffuser angle on the performance, the flowrate and the volumetric efficiency of the micropumps with different diffuser angles from $30^{\circ}$ to $45^{\circ}$ were studied by the numerical simulation. The numerical simulation results were compared with the experimental data. The findings reveal that the micropump with the diffuser angle of $45^{\circ}$ can achieve the flowrate of $5.4 \mathrm{ml}_{\mathrm{min}} \mathrm{m}^{-1}$ and the maximum back pressure of $2.82 \mathrm{kPa}$ in the optimum operating condition, $300 \mathrm{Vp}-\mathrm{p}$ for the driving voltage and $25 \mathrm{~Hz}$ for the frequency. The suitable range of the diffuser angle is about from $30^{\circ}$ to $45^{\circ}$. When the maximum Reynolds number is over 600, the entrained flowrate caused by Coanda effect can contribute a over $50 \%$ volumetric efficiency to the micropump.
\end{abstract}

Key words: Valveless / Piezoelectric micropump / Coanda effect

\section{Introduction}

Micro-fluidic system has a promising future in the life sciences and chemical analysis fields [1-3]. Gene chips and biochips based on micro-fluidic technology have been widely utilized in DNA sequencing, pathological genetic analysis and drug reactions $[4,5]$. In micro-fluidic systems, a micropump functions as a crucial device to pump the fluid to overcome the resistance of the system. Micropumps can be classified into mechanical and nonmechanical ones generally according to the principle how the fluid is transported [6]. Non-mechanical micropumps such as the electroosmotic [7], magnetohydrodynamic [8], and electrowetting [9] micropumps drive the fluid directly by electric, magnetic or other types of energy without moving parts. However, they are not widely utilized for the complex structures and the relatively harsh working conditions as well as the low outlet pressure [10]. The mechanical micropumps drive the fluid with vibrating diaphragms or rotating parts $[11,12]$, for instance,

\footnotetext{
${ }^{a}$ Corresponding author: xiuhua.he@ujs.edu.cn
}

the vibrating diaphragm micropumps [13], rotary micropumps [14], and ferrofluid micropumps [15]. The piezoelectric micropumps belonging to the vibrating diaphragm micropumps may utilize valves to control the flow direction. However, there are lots of disadvantages for micropumps with valves because there is a risk of reduction in performance and reliability due to wear and fatigue of the valves, a high pressure loss near the check valves and a risk of valve clogging [16].

The piezoelectric micropump with no moving valves is one of the most-investigated types of micropumps with simple structure and great miniaturization potential. Simultaneously, there is a great advantage for the valveless piezoelectric micropumps to transport the solution containing large cells or particles that can easily cause valve clogging [17].

The first valveless micropump based on diffuser/nozzle with small diffuser angle was fabricated by Stemme and Stemme in 1993 [18]. Then Gerlach and Wurmus fabricated another diffuser/nozzle valveless pump with the large diffuser angle diffuser/nozzle by silicon 


\section{Nomenclature}

\begin{tabular}{|ll|}
\hline$A$ & Throat area \\
$b$ & Width of straight pipes \\
$D_{\mathrm{h}}$ & Hydraulic diameter \\
$d$ & Width of throat \\
$f$ & Frequency \\
$h$ & Depth of wall-attached jet element \\
$L$ & Channel length \\
$L_{0}$ & Minimum diffuser length \\
$L_{1}$ & Diffuser length \\
$L_{2}$ & Length of straight pipes \\
$q$ & Instantaneous volume changing rate of chamber \\
$q_{\max }$ & Maximum instantaneous volume \\
& changing rate of chamber \\
$q_{\mathrm{outlet}}$ & Instantaneous flowrate through outlet \\
$R e$ & Instantaneous Reynolds number \\
$R e_{\max }$ & Maximum instantaneous Reynolds number \\
$R e_{\mathrm{t}}$ & Transitional Reynolds number for short channels \\
$r$ & Fillet radius \\
$T$ & Period \\
$t$ & Time \\
$U$ & Velocity at boundary \\
$U_{m}$ & Maximum velocity at boundary \\
$u$ & Mean velocity across throat \\
$u_{\max }$ & Maximum mean velocity across throat \\
$V_{c}$ & Volume changing of pump chamber \\
$\eta$ & Volumetric efficiency \\
$\theta$ & Diffuser angle \\
$X$ & Wetted perimeter of throat \\
$v$ & Kinematic viscosity of water \\
\hline & \\
\hline
\end{tabular}

technology [19]. Olsson, et al. presented a valveless planar fluid pump with two chambers [16]. Some special tubes working on the similar principles as the diffuser/nozzles have been developed, such as Tesla tube [20], vortex tube [21], bifurcated tube [22], three-way tube [23, 24], Additionally, there are valveless piezoelectric micropumps based on other principles. A planar bidirectional valveless peristaltic micropump with three chambers by deep reactive ion etching technology (DRIE) was reported by Lee et al. [25]. Jong et al. proposed an air mciropump based on synthetic jet by polydimethylsiloxane (PDMS) replication technology [26]. A valveless micropump driven by acoustic streaming was fabricated by Youngki Choe and Eun Sok Kim [27].

The diffuser/nozzle valveless micropumps are the most common type of the piezoelectric micropumps. The micropumps work by a vibrating diaphragm producing an oscillating chamber volume, which together with the two fluid-flow-rectifying diffuser/nozzle elements, creates a one-way fluid flow [18]. And there are a lot of researches reported about them $[18,28]$. The performance of this micropump is strongly dependent on the design of the diffuser/nozzle element. However, there is small difference between the loss coefficients of nozzle and diffuser at low Reynolds numbers. So the flowrate and the volumetric efficiency are low for the diffuser/nozzle valveless micropumps.

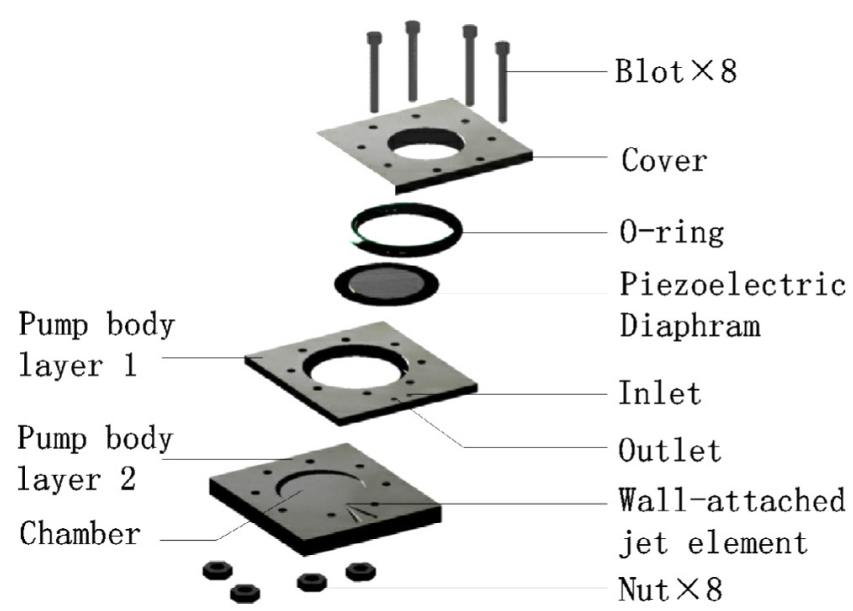

Fig. 1. Explosive view of the micropump.

In order to improve the flowrate and the volumetric efficiency of the valveless piezoelectric micropump, the Coanda effect serves as the working principle of the micropump in this study. The Coanda effect is the tendency of a fluid jet to be attracted to a nearby surface [29]. The principle was named after Romanian aerodynamics pioneer Henri Coanda, the first to recognize the practical application of the phenomenon in aircraft development. In the field of microfluidic devices, the effect has been applied on the fluidic microoscillator [30] and micromixer [31]. This piezoelectric valveless micropump based on the Coanda effect processes good performance at low Reynolds numbers for the appearance of the Coanda effect doesn't require very high flow velocity.

A valveless piezoelectric micropump for transporting liquid based on the Coanda effect was designed and fabricated by Polymethylmethacrylate (PMMA). An experiment was carried out to obtain the performance and search for the optimum operating condition of the micropump with the diffuser angle of $45^{\circ}$. Then a numerical simulation supported by the experiment results was done to study the working progress, the effects of the structure parameter, the diffuser angle, as well as the wall-attached jet on the performance of the micropump with different maximum Reynolds numbers.

\section{Structure and principle}

The structure of the valveless piezoelectric micropump based on the Coanda effect is shown in Figure 1. It consists of a pump body, a cover and a piezoelectric diaphragm. The diaphragm is sealed with an O-ring between the bolting cover and the pump body. The pump body with the inlet and the outlet is glued or thermally bonded by two layers manufactured with the material like silicon or PMMA. The pump chamber and the flow channel including the wall-attached jet element are fabricated in the pump body layer 2 .

The wall-attached jet element shown in Figure 2 is the key part of the micropump. It is made up of a diffuser 


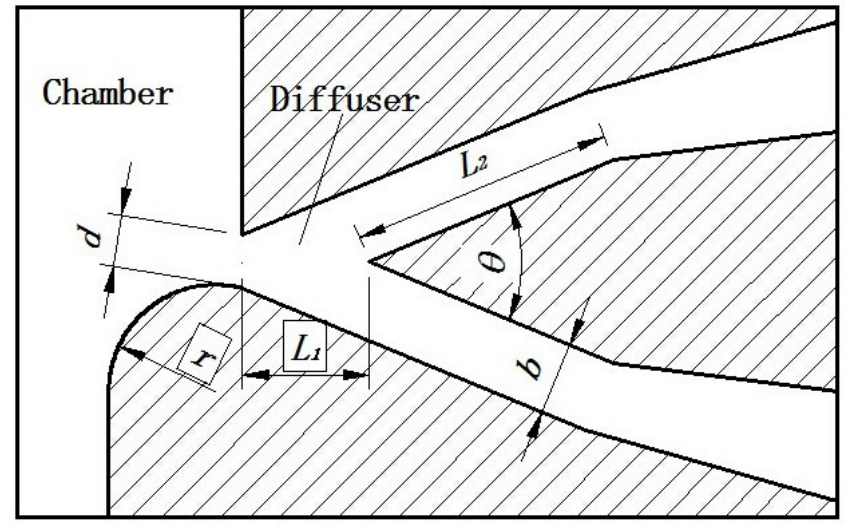

Fig. 2. Schematic of the wall-attached jet element.

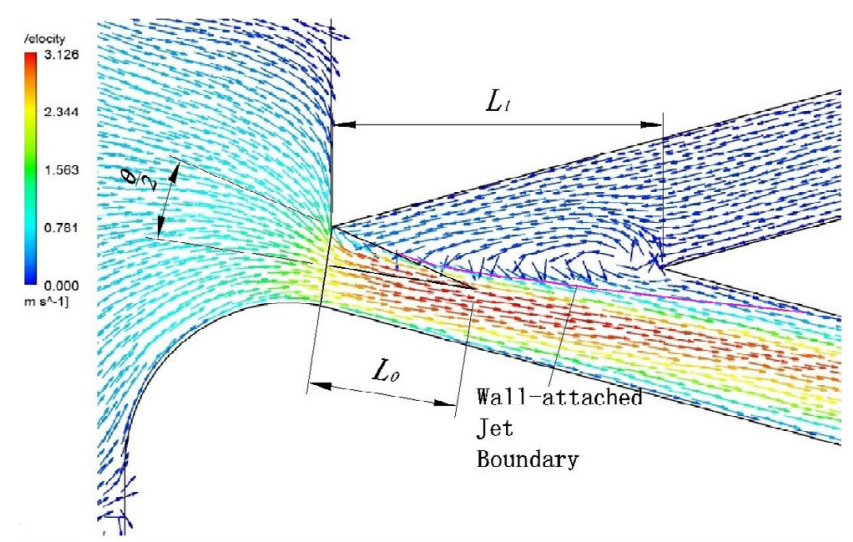

Fig. 3. Definition of the ideal diffuser length $L_{0}$ in velocity field.

and two straight pipes. There is a fillet on one side in the throat where the diffuser connects with the pump chamber, and a sharp corner on the other side.

The diffuser angle $\theta$ is to be discussed in the sections below. It is not convincing if the diffuser length is a constant when the diffuser angle is changing for the width of the channels $b$ would be very small with the little diffuser angle, making the wall-attached jet can not be fully developed. Therefore, a diffuser angle dependent diffuser length $L_{1}$ is required to ensure a fully-developed jet. The diffuser length $L_{1}$ is defined as shown in Figure 3. Ideally, the jet flow could be immediately attached to the wall after spraying out from the pump chamber, and there would be a straight jet boundary. Thus the minimum length of the diffuser $L_{0}$ can be calculated by the simple geometry in Equation (1).

$$
L_{0}=\frac{d}{2} \cot \frac{\theta}{2}
$$

Actually, the jet boundary is not a straight line for the width of the wall-attached jet becoming larger as shown in Figure 3. Consequently a larger diffuser length $L_{1}$ is required to make sure the jet fully developed. In this study, $L_{1}=2 L_{0}$.

A working cycle of the micropump can be divided into the suction process and the pumping process as Figure 4 shows. In the suction process, the fluid is sucked almost equally through both the inlet and the outlet due to the negative pressure in the chamber caused by a upward moving diaphragm driven by a $\mathrm{AC}$ power supply. When it turns to the pumping process, the fluid in the chamber is sprayed out as a jet with the diaphragm moving in the opposite direction. According to the Coanda effect, the jet flow is attached to the fillet wall and the fluid in the chamber will all discharge through the outlet because of the unsymmetric structure in the throat. Simultaneously, some fluid outside the pump can be sucked through the inlet by the entrainment of the jet flow and then joins the jet flow, flowing out through the outlet, too. The flowrate caused by this phenomenon, called as the entrained flowrate, is the highlight of the principle, which can improve the net flowrate and the volumetric efficiency of the micropump remarkably. The volumetric efficiency defined as (2) can be up to or even more than $50 \%$.

$$
\eta=\frac{\int_{0}^{T} q_{\text {outlet }} \mathrm{d} t}{V_{\mathrm{c}}}
$$

where $T$ is the cycle time, $q_{\text {outlet }}$ is the instantaneous flow rate through the outlet, and $V_{\mathrm{c}}$ is the volume changing of the pump chamber.

\section{Experiment}

\subsection{Micropump fabrication}

A valveless micropump with the diffuser angle of $45^{\circ}$ is shown in Figure 5. Polymethylmethacrylate (PMMA) is utilized to fabricate the cover as well as the pump body. The wall-attache jet element in the pump body is formed with two layers thermally bonded together. The pump body and the cover are combined to be a whole structure by tightened force controlled bolted connection. The geometric parameters of the micropump used in the experiment are shown in Table 1.

\subsection{Experimental setup}

The schematic and the equipments of the experiment are shown in Figure 6. A series of sinusoidal voltages with different frequencies to drive the micropump was provided by the function generator (Tektronix, AFG3022B) and amplified by a power amplifier (Fo Neng, HVP-1070B). The oscilloscope (Tektronix, TBS1022) was used to monitor the current voltage accurately. The output pressure around the outlet was measured by a Pressure sensor (Omega, PX309-001GV) with the measuring range of 0$7 \mathrm{kPa}$ and accuracy of $0.25 \%$, and it was driven by a DC electrical source. The volumetric method was used to obtain the net flowrate of the micropump in $5 \mathrm{~min}$. The medium was deionized water.

A high-speed photograph (OLYMPUS I-SPEED 3) was utilized to obtain the instantaneous volume changing rate of the chamber. Two glass burettes connecting 


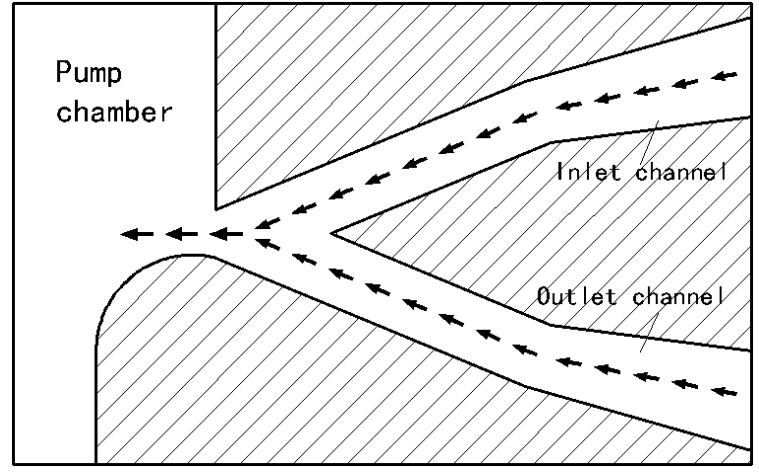

(a)

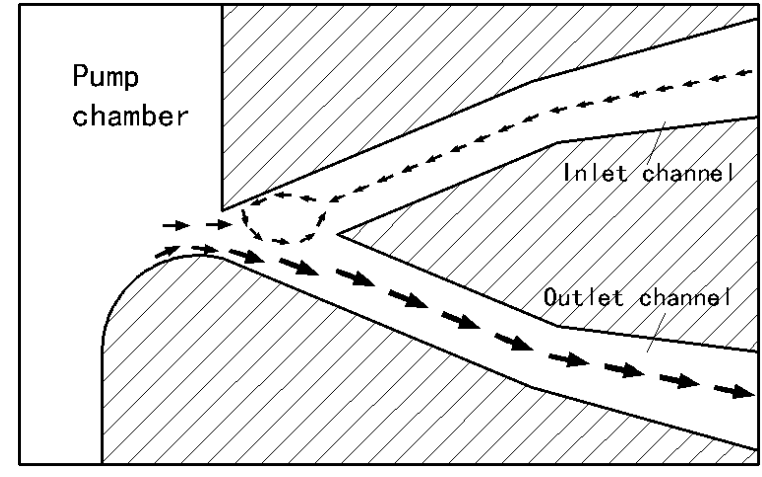

(b)

Fig. 4. Principle of the micropump. (a) The suction process. (b) The pumping process.

Table 1. Parameters of the piezoelectric diaphram and the micropump in the experiment.

\begin{tabular}{cc}
\hline Geometric parameter & Value \\
\hline Piezoelectric vibrator & Murata 7BB-35-3 \\
Diameter of piezoelectric layer $(\mathrm{mm})$ & 25 \\
Thickness of piezoelectric layer $(\mathrm{mm})$ & 0.3 \\
Diameter of copper layer $(\mathrm{mm})$ & 35 \\
Thickness of copper layer $(\mathrm{mm})$ & 0.2 \\
Inside diameter of O-ring $(\mathrm{mm})$ & 35 \\
Outside diameter of O-ring $(\mathrm{mm})$ & 31 \\
Diameter of inlet/outlet orifice $(\mathrm{mm})$ & 2 \\
Diameter of pump chamber $(\mathrm{mm})$ & 35 \\
Depth of pump chamber $(\mathrm{mm})$ & 0.7 \\
Area of throat $\left(\mu \mathrm{m}^{2}\right)$ & $200 \times 200$ \\
Diffuser angle $\left(^{\circ}\right)$ & 45 \\
Fillet radius $(\mu \mathrm{m})$ & 400 \\
\hline
\end{tabular}

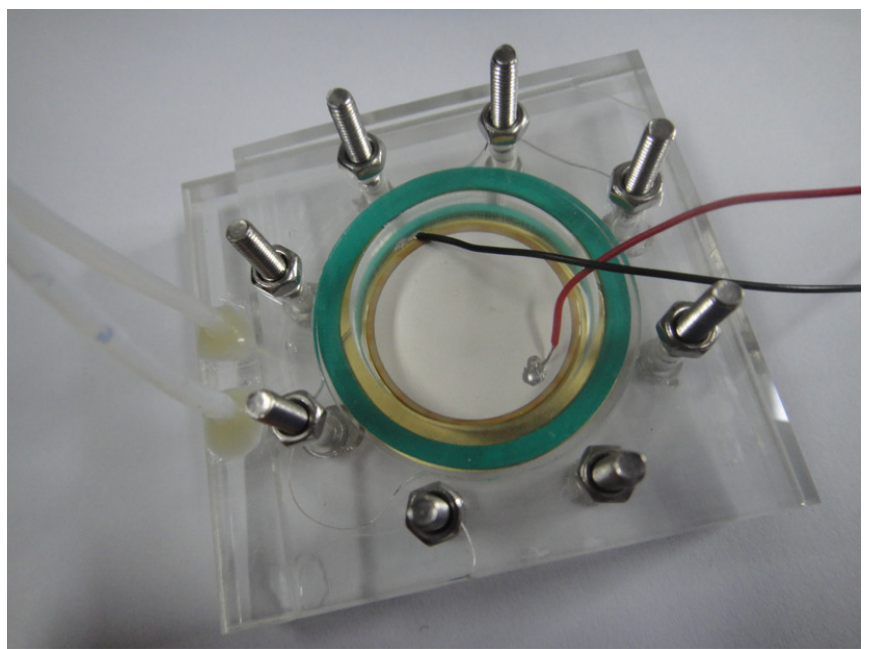

Fig. 5. The micropump applying Coanda effect with the diffuser angle of $45^{\circ}$.

with the inlet and the outlet respectively were taken by 500 frames per second. The instantaneous volume changing rate of the chamber can be calculated by adding the instantaneous flowrate in the two burettes together.

\subsection{Experimental results and discussion}

Figure 7 shows the net flowrate for a series of driving frequencies and voltages. Obviously, the higher voltage is supplied, the larger flowrate can be obtained. However, an overlarge voltage should be avoided for it can produce excessive vibration of the diaphragm, leading to the appearance of bubbles in the chamber, which can produce a decline of the performance. A number of bubbles could be observed during the experiment when the voltage was more than $300 \mathrm{Vp}-\mathrm{p}$, and the flowrate declined obviously.

For the micropump studied in the experiment, the net flowrate in a cycle is increasing with the driving frequency and reaches to the maximum value at $25 \mathrm{~Hz}$, then goes down with the frequency over $25 \mathrm{~Hz}$. The maximum net flowrate $5.4 \mathrm{ml} . \mathrm{min}^{-1}$ can be observed when the frequency is $25 \mathrm{~Hz}$ and the voltage is $300 \mathrm{Vp}$-p

The results are similar for the maximum back pressure with different driving frequencies and voltages just as shown in Figure 8. But the maximum back pressure reaches to the maximum value at the point of $25 \mathrm{~Hz}$ or $30 \mathrm{~Hz}$ for different voltages. It can reach $2.82 \mathrm{kPa}$ when the driving voltage is $300 \mathrm{Vp}-\mathrm{p}, f=25 \mathrm{~Hz}$ or $30 \mathrm{~Hz}$ (with the same value).

Based on the results above, it suggests that the optimal driving frequency for this type of micropump is about $25 \mathrm{~Hz}$, and the voltage should not be over $300 \mathrm{Vp}-\mathrm{p}$. 


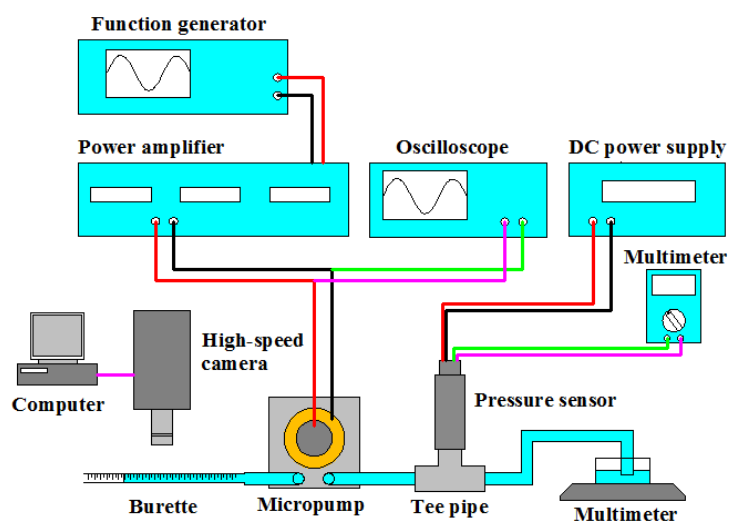

(a)

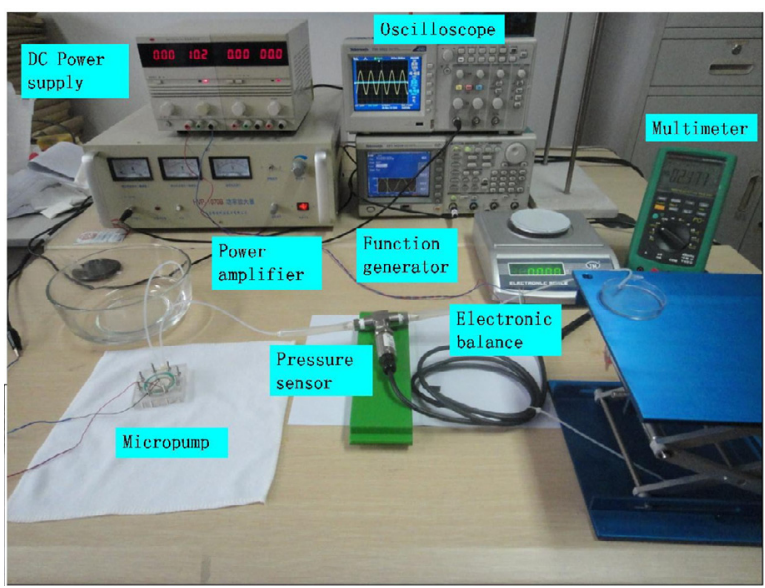

(b)

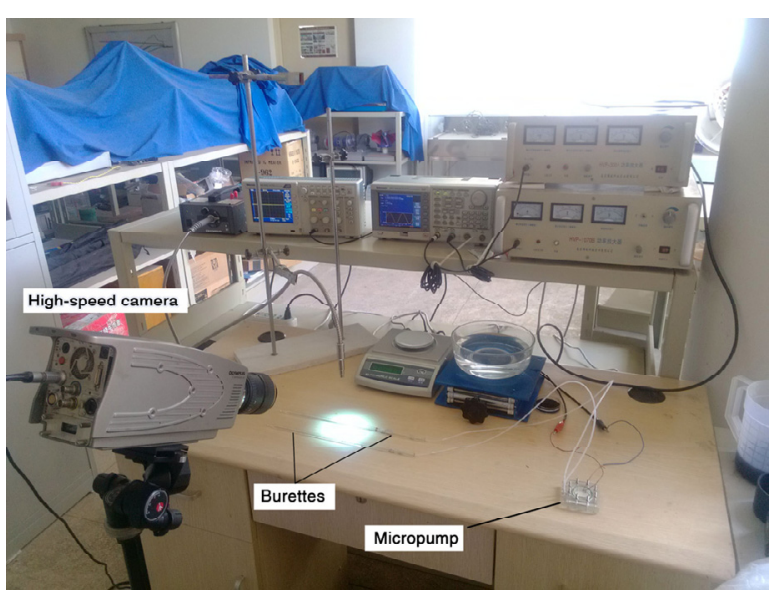

(c)

Fig. 6. The experimental schematic and equipment. (a) Schematic. (b) Equipment (1). (c) Equipment (2).

\section{Numerical simulation}

The commercial CFD software, Analysis 14.5, and the corresponding geometry and mesh generating software, Gambit 2.4.6, were utilized for numerical simulation. The working medium was water at $25^{\circ} \mathrm{C}$. The problem was

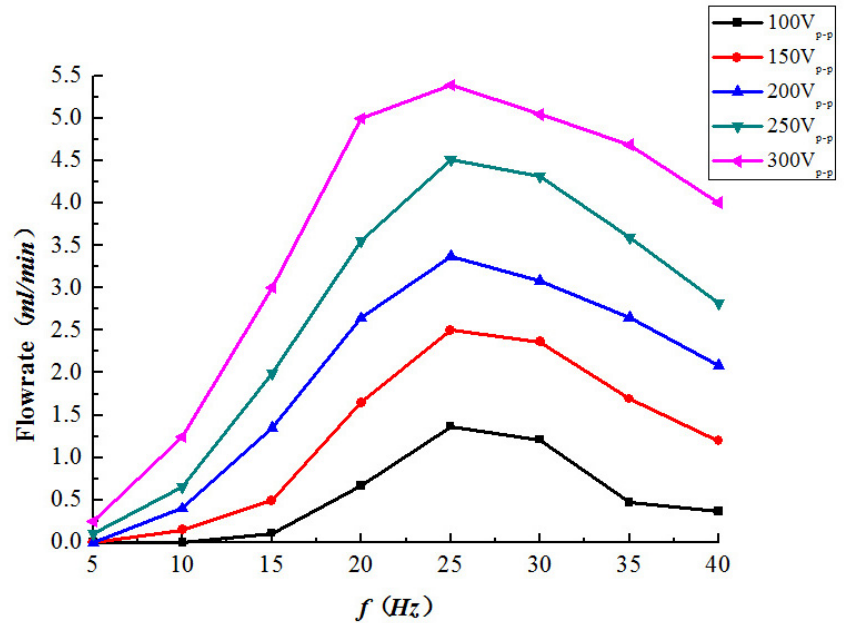

Fig. 7. Net flowrate of the micropump with the diffuser angle of $45^{\circ}$ for a series of driving frequencies and voltages.

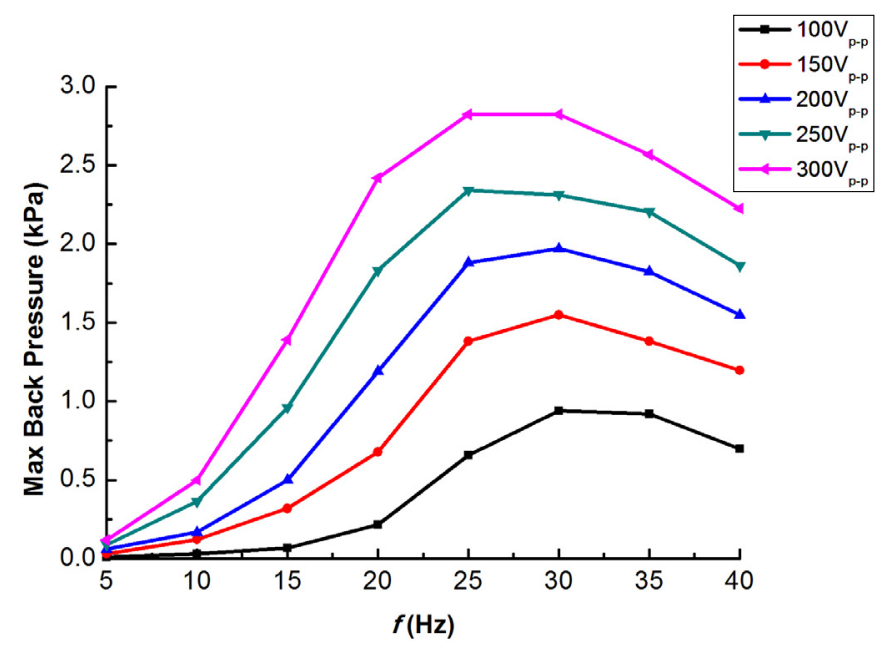

Fig. 8. Maximum back pressure of the micropump with the diffuser angle of $45^{\circ}$ for a series of driving frequencies and voltages.

three-dimensional, unsteady state, isothermal flow. The compressibility effects were ignored.

\subsection{Geometry and mesh}

The computational domain generated in Gambit 2.4.6 is shown in Figure 9. The diffuser angles $\theta$ from $15^{\circ}$ to $60^{\circ}$ were studied in the numerical simulation for the diffuser angle has a significant impact on the performance of the micropump. The other geometrical parameters of the micropump are shown in Table 2 below.

The computational domain is meshed mostly using the hexahedral structured scheme that results in the following mesh arrangement shown in Figure 10. The meshes were refined around the throat where the gradients were large. There is less than $3 \%$ deviation of the flowrate by increasing the grid number from about 800000 to 1000000 . 
Table 2. Parameters of the wall-attached jet element in the numerical simulation.

\begin{tabular}{cc}
\hline Structure size & Value \\
\hline Area of throat $d \times d\left(\mu \mathrm{m}^{2}\right)$ & $200 \times 200$ \\
Depth of wall-attached jet element $h(\mu \mathrm{m})$ & 200 \\
Length of straight pipes $L_{2}(\mu \mathrm{m})$ & 1000 \\
Length of diffuser $L_{1}$ & $2 L_{0}$ \\
Fillet radius $r(\mu \mathrm{m})$ & 400 \\
\hline
\end{tabular}

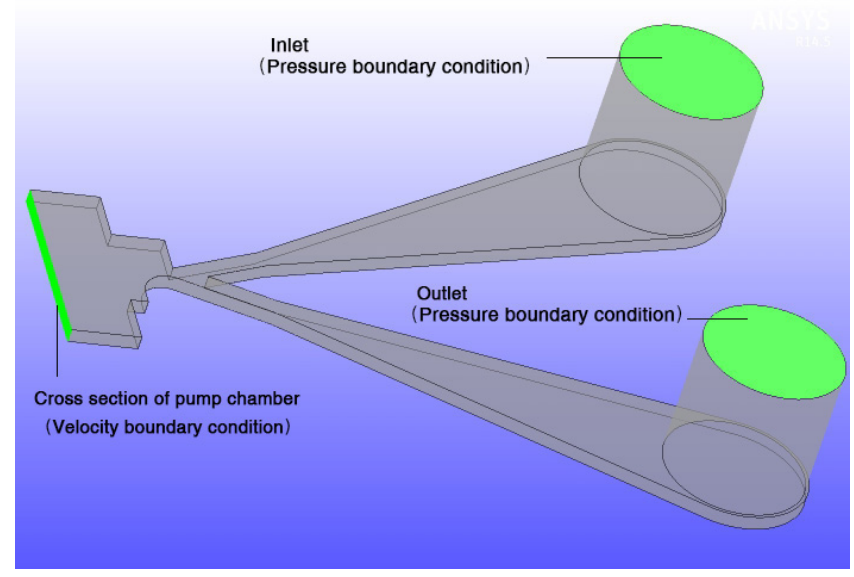

Fig. 9. Computational domain.

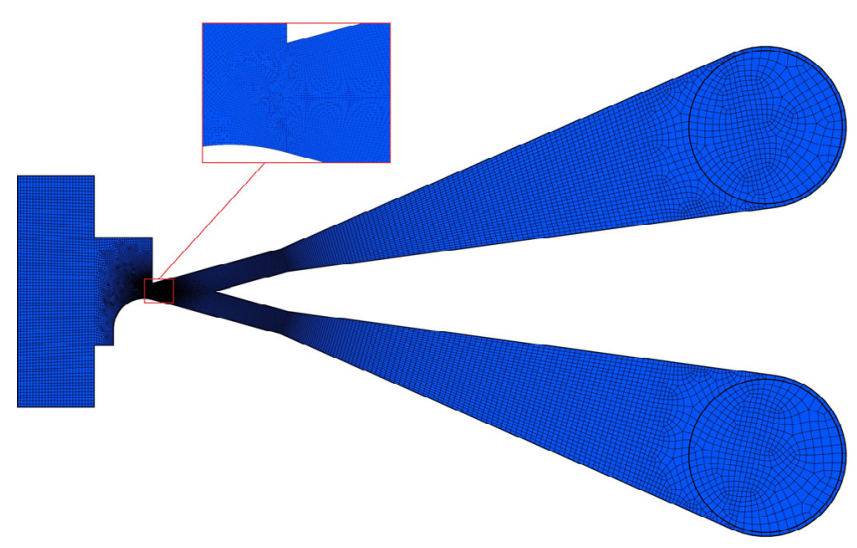

Fig. 10. Computational mesh.

Therefore, the total grid number 800000 was suitable for the numerical simulation.

\subsection{Boundary condition}

The pressure boundary condition was set at both inlet and outlet of the micropump. The velocity boundary condition was used on the pump chamber's cross section shown in Figure 9 to simulate the oscillation of the piezoelectric diaphragm. For the piezoelectric diaphragm was stimulated by the sinusoidal alternating voltage, the
Table 3. $R e_{t}$ for the micropumps with different diffuser angles.

\begin{tabular}{cccc}
\hline$\theta\left(^{\circ}\right)$ & $L=r+L_{1}+L_{2}(\mathrm{~mm})$ & $\frac{L}{D_{\mathrm{h}}}$ & $R e_{\mathrm{t}}=30 \frac{L}{D_{\mathrm{h}}}$ \\
\hline 15 & 3.02 & 15.1 & 453 \\
30 & 2.3 & 11.5 & 345 \\
45 & 1.98 & 9.9 & 297 \\
60 & 1.85 & 9.25 & 278 \\
\hline
\end{tabular}

velocity of the fluid on the pump chamber's cross section was set as (3)

$$
U=U_{m} \sin \left(\frac{2 \pi}{T} t\right)=U_{m} \sin (2 \pi f t)
$$

where, $U_{m}$ is the maximum velocity applied in the boundary condition, $T$ is the period and $f=1 / T$ is the working frequency.

The other surfaces are considered as impermeable walls.

\subsection{Flow model}

The instantaneous Reynolds number is defined as (4)

$$
R e=\frac{\left(\frac{4 A}{\chi}\right) u}{v}=\frac{\mathrm{d} u}{v}
$$

where, $u$ is the mean velocity across the throat; $v$ is the kinematic viscosity of water. $A$ and $\chi$, are the area and wetted perimeter of the throat of the diffuser respectively.

To determine whether a given flow pattern is laminar or turbulent, it is common practice to evaluate the Reynolds number and compare it to the macroscopical transitional number 2000 or 2300. However, the transitional Reynolds number seems to have little relevance to the microfluidic devices for their small size and various structures. Based on the results presented by Gravesen et al. [32], the transitional Reynolds number for short channels $R e_{\mathrm{t}}$ can be defined as $30 L / D_{\mathrm{h}}$ when the $2<$ $L / D_{\mathrm{h}}<50$, where $L$ is the length of the channel, $D_{\mathrm{h}}$ is the hydraulic diameter $(4 A / \chi)$ of the throat. In this study, the $R e_{\mathrm{t}}$ of the micropumps with different diffuser angles are shown in Table 3.

When $R e>R e_{\mathrm{t}}$, the SST turbulent model was utilized. The SST model can be used as a low Re turbulence model with the high accurate prediction of flows with strong adverse pressure gradients and separation [33,34].

\subsection{Comparison between numerical simulations and experiments}

A comparison between numerical simulation and experiments was carried out to test the accuracy of the numerical simulation. Knowing the maximum volume changing rate of the chamber in the experiment, the maximum Reynolds number can be calculated, so the corresponding numerical simulation can be carried out. 


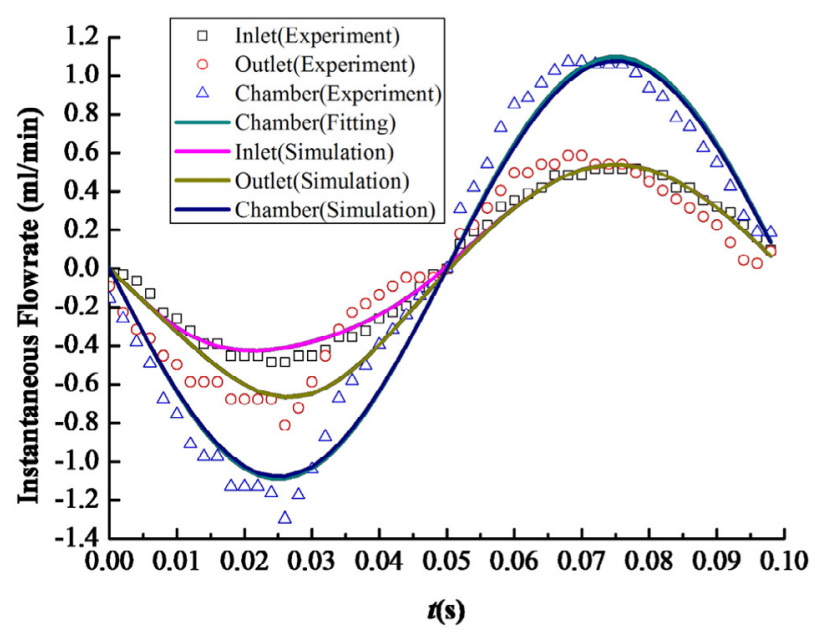

Fig. 11. Comparison between the experimental and numerical simulation obtained results.

The non-linear regression analysis of the experimental data for $50 \mathrm{Vp}$-p and $10 \mathrm{~Hz}$, leads to a fitting sinusoidal function (5) describing the instantaneous volume changing rate of the chamber. The $\mathrm{P}$-value (probability of the value being significant with a $95 \%$ confidence) is $10^{-5}$, thus the fitting function is accepted $(P<0.05)$.

$$
q=-1.092 \sin (20 \pi t)+0.004\left(\mathrm{ml}_{\mathrm{min}}{ }^{-1}\right) .
$$

The maximum instantaneous Reynolds number is

$$
R e_{\max }=\frac{u_{\max } d}{v}=\frac{q_{\max } / d}{v}
$$

In the situation $q_{\max }$ is $1.088 \mathrm{ml} \cdot \mathrm{min}^{-1}$, the $R e_{\max }$ is 92 .

A comparison between the experiment and numerical simulation results is plotted in Figure 11. The positive value means the fluid is sucked through the inlet/outlet, and the negative value represents the opposite case. So the net flowrate in a cycle can be calculated as the area enclosed by the curves of the inlet and the outlet.

By integrating the inlet and the outlet instantaneous flowrate, the net flowrate is $0.0325 \mathrm{ml} . \mathrm{min}^{-1}$ and $0.0247 \mathrm{ml} \cdot \mathrm{min}^{-1}$ respectively for the experiment and the numerical simulation. The deviation of the flowrate is $24 \%$, which is probably due to the additional resistance caused by interfacial tension in the burettes during the experiment.

\subsection{Simulation results and discussion}

\subsubsection{Working process}

The working process of the micropump can be specialized in Figure 12. It shows the instantaneous flowrate through the inlet and the outlet when $R e_{\max }$ is 1000 and the diffuser angle is $45^{\circ}, f=10 \mathrm{~Hz}$. The former half cycle is the pumping process and the latter is the suction process. There is little difference during the suction process

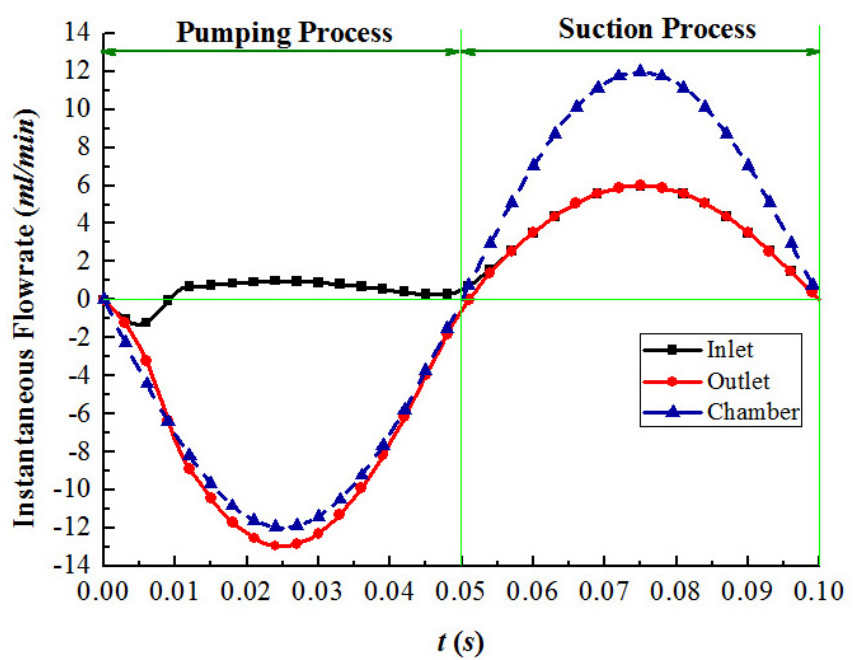

Fig. 12. Instantaneous flowrates of inlet and outlet and volume changing rate of the chamber $\left(R e_{\max }=1000 \theta=45^{\circ}\right.$ $f=10 \mathrm{~Hz})$.

for the flowrates through the inlet and the outlet almost equal. But in pumping process, when about $t=0.05 T$, the curve of the instantaneous flowrate through the inlet begins to separate from that of the outlet and then rises over the zero line, which means there is some fluid being entrained into the pump through the inlet and then pumped out through the outlet. It is not appeared in the situation of Figure 11 because the Reynolds number is too low. Figures $13 \mathrm{a}$ and $13 \mathrm{~b}$ show its velocity vector and the pressure nephogram within the wall-attached jet element during a whole cycle respectively. And the entrainment phenomenon can be seen from $t=0.2 T$ to $t=0.4 T$ more clearly.

\subsubsection{Effects of the diffuser angle}

Through the numerical simulation, a suitable diffuser angle can be found. When the back pressure is zero, the net flowrate at different $R e_{\max }$ and diffuser angles are plotted in Figure 14. When $R e_{\max }$ is less than 400, the maximum flowrate is obtained at $\theta=45^{\circ}$. When $R e_{\max }$ is over 400 , the micropump of $\theta=30^{\circ}$ has the largest flowrate.

Figure 15 illustrates the volumetric efficiency for different $R e_{\max }$ and different diffuser angles. The micropumps with the diffuser angle of $30^{\circ}$ and $45^{\circ}$ still possess the better performance. The maximum volumetric efficiency is $56.12 \%$ as $R e_{\max }=1000, \theta=30^{\circ}$.

Figure 16 shows the instantaneous flowrate through the inlet and the outlet when $R e_{\max }$ is 600 . For the micropumps with the diffuser angle of $30^{\circ}$ and $45^{\circ}$, the two curves separate from each other earlier than the others. That means that the jet from the chamber attaches to the wall earlier and the Coanda effect lasts a longer period within a cycle, leading to a larger flowrate than the others. Moreover, the entrained flowrate through the inlet in the pumping process is larger for the micropump with 
Xiuhua He et al.: Mechanics \& Industry 17, 204 (2016)

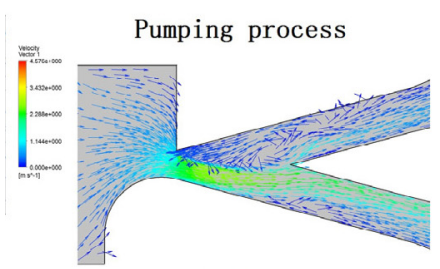

$t=0.1 T$

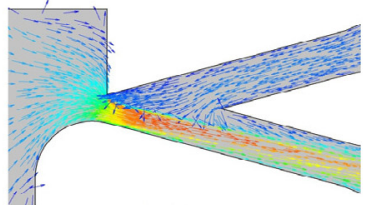

$t=0.2 T$

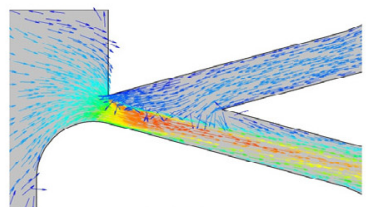

$t=0.3 T$

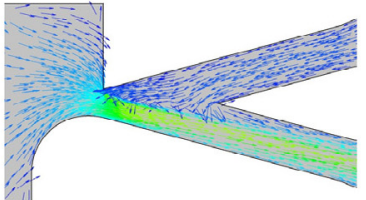

$t=0.4 T$

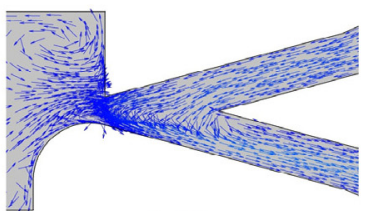

$t=0.5 T$
Suction process

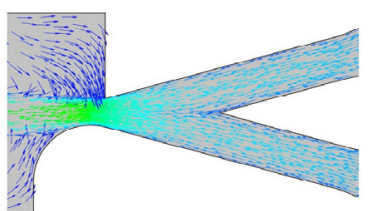

$t=0.6 T$

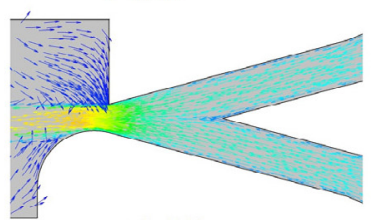

$t=0.7 T$

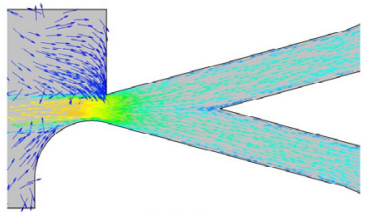

$t=0.8 T$

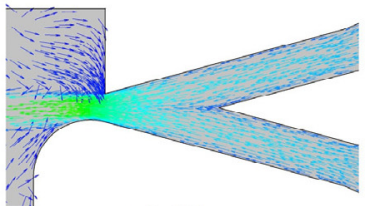

$t=0.9 T$

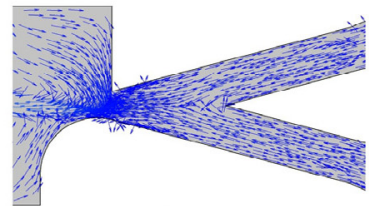

$t=1 T$

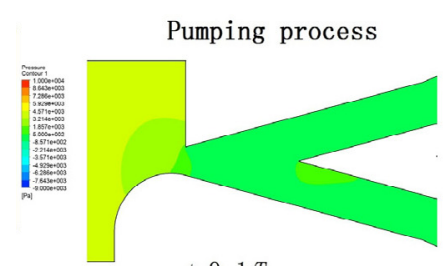

$t=0.1 T$

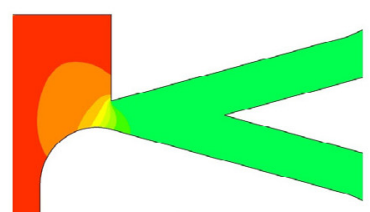

$t=0.2 T$

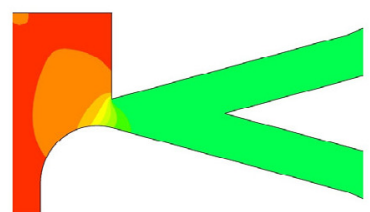

$t=0.3 T$

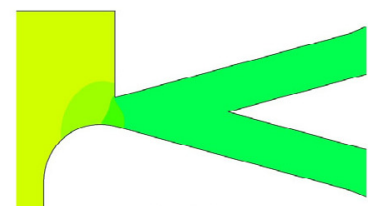

$t=0.4 T$

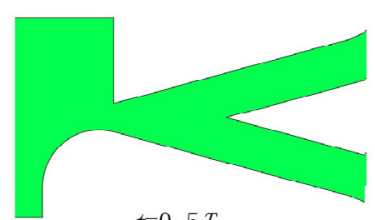

$t=0.5 T$
Suction process

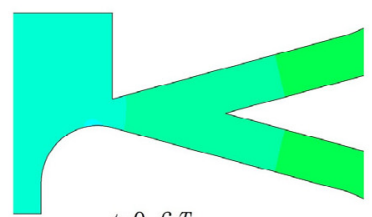

$t=0.6 T$

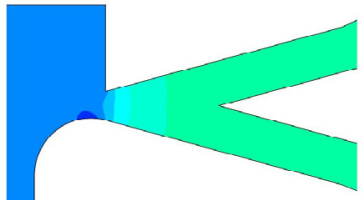

$t=0.7 T$

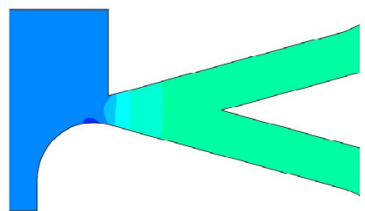

$t=0.8 T$

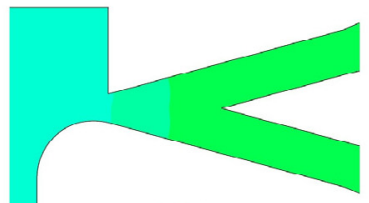

$t=0.9 T$

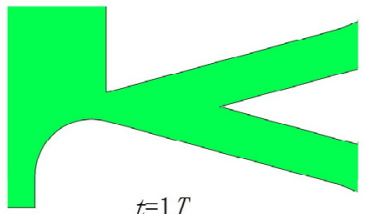

(b)

(a)

Fig. 13. (a) Velocity field (b) pressure nephogram within the wall-attached jet element during a whole cycle $\left(R e_{\max }=600\right.$, $\left.f=10 \mathrm{~Hz}, \theta=30^{\circ}\right)$.

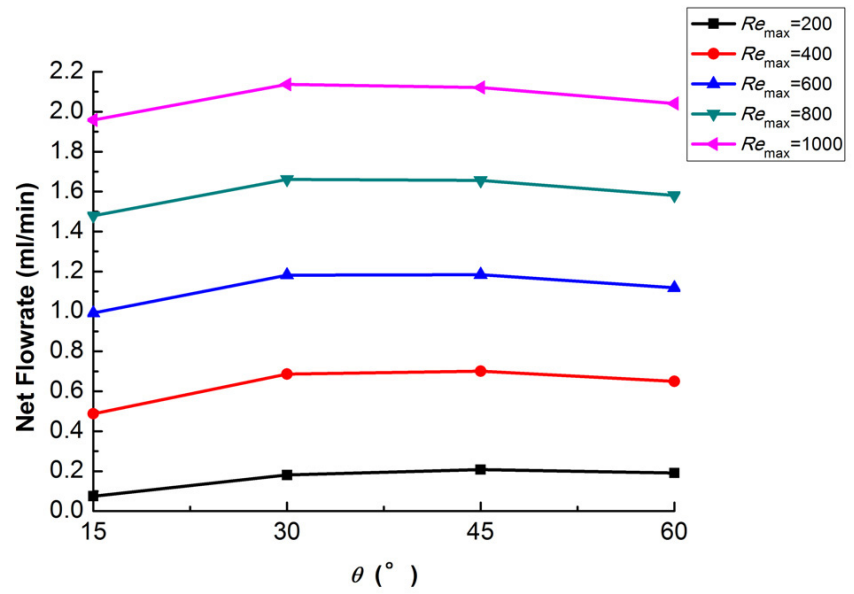

Fig. 14. Net flowrates at different $R e_{\max }$ and diffuser angles $(f=10 \mathrm{~Hz})$.

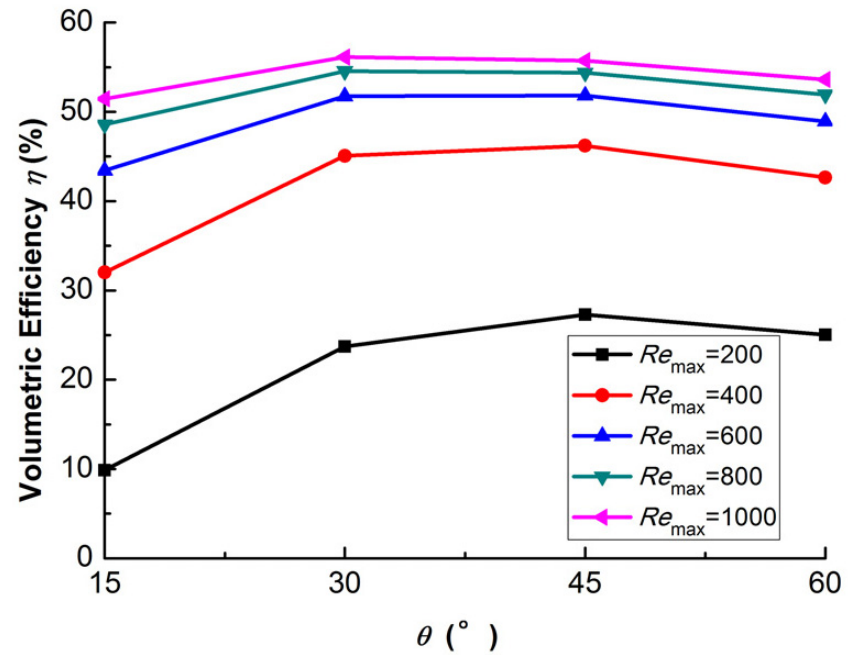

Fig. 15. Volumetric efficiency at different $R e_{\max }$ and diffuser angles $(f=10 \mathrm{~Hz})$. 


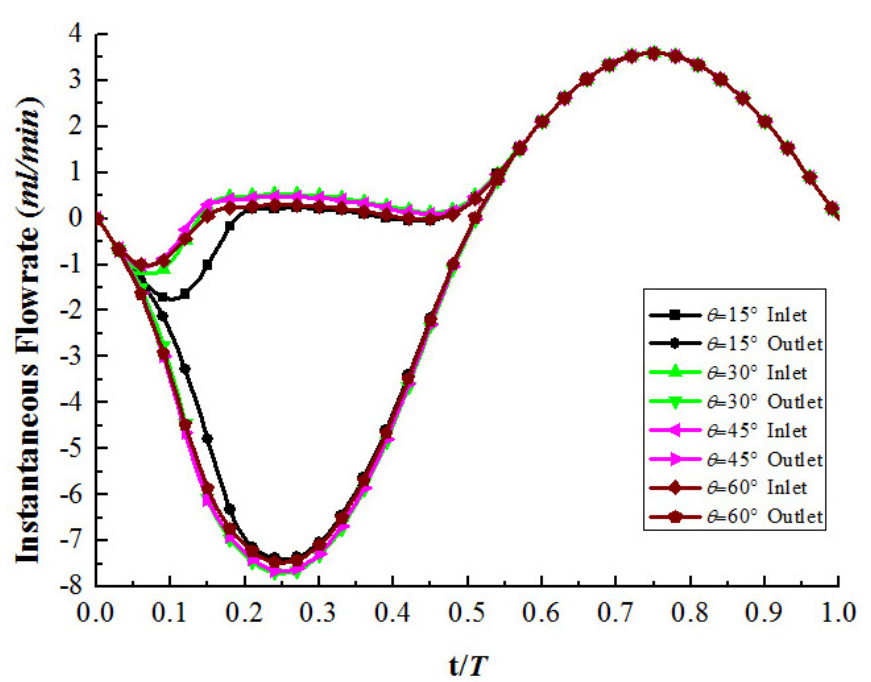

Fig. 16. Instantaneous flowrate through the inlet and the outlet for different diffuser angles $\left(R e_{\max }=600, f=10 \mathrm{~Hz}\right)$.

the diffuser angle of $30^{\circ}$ and $45^{\circ}$ than the others, which also contributes to the larger net flowrate and higher volumetric efficiency.

Therefore, the findings above suggest the suitable range of the diffuser angle about from $30^{\circ}$ to $45^{\circ}$ for the large flowrate and the high volumetric efficiency.

\subsubsection{Contribution of the wall-attached jet}

It is plotted in Figure 15 that as $R e_{\max }$ increases from 200 to 600 , the volumetric efficiency improves obviously. This is because when $R e_{\max }$ is low, the jet can not attach to the wall completely in the pumping process and there is still some fluid flowing out through the inlet, leading to the low outlet flowrate, as shown in Figure 17a. As $R e_{\max }$ rises, by the stronger influence of the Coanda effect, there is less and less fluid flowing out through the inlet during the pumping process. Moreover, when $R e_{\max }=400$, the entrained flowrate caused by the wall-attached jet appears as shown in Figure 17b, resulting in an obvious increase of the volumetric efficiency.

When $R e_{\max }=600$, the entrainment becomes even stronger as shown in Figure 17c, so the volumetric efficiency can achieve over $50 \%$. But according to Figure 18, the entrained flowrate doesn't increase obviously as $R e_{\max }$ is from 800 to 1000 , thus there is little difference between the curves of volumetric efficiency of $R e_{\max }=800$ and $R e_{\max }=1000$ in Figure 15.

\section{Conclusions}

A valveless piezoelectric micropump for transporting liquid based on the Coanda effect was designed and fabricated by Polymethylmethacrylate (PMMA). An experiment was carried out to obtain the performance and

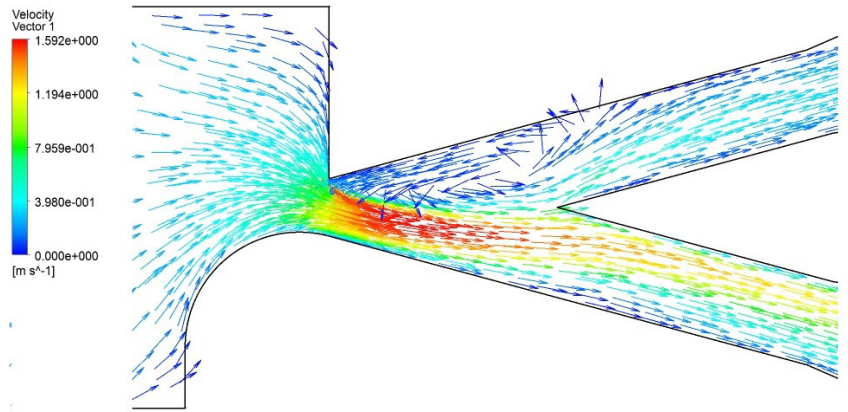

(a)

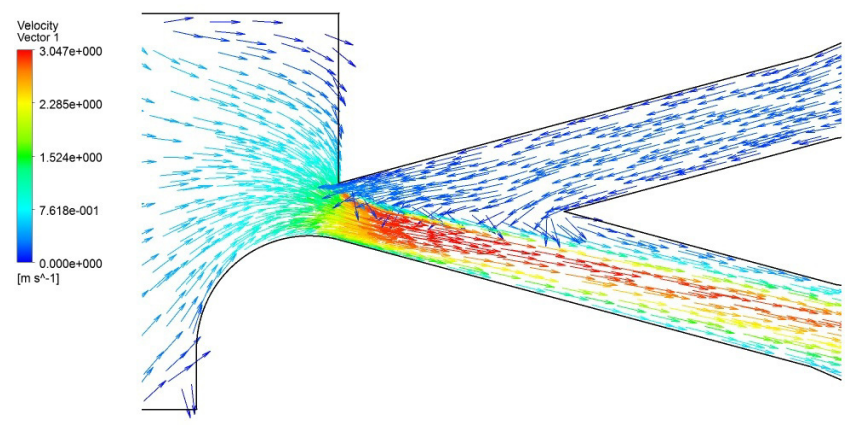

(b)

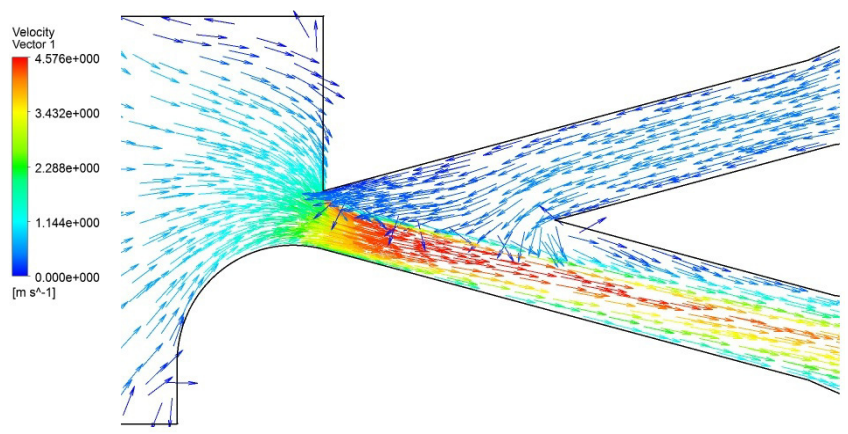

(c)

Fig. 17. Velocity field within the wall-attached jet element $\left(t=1 / 4 T, \theta=30^{\circ}, f=10 \mathrm{~Hz}\right.$ ). (a) $R e_{\max }=200$. (b) $R e_{\max }=$ 400. (c) $R e_{\max }=600$.

search for the optimum operating condition of the micropump with the diffuser angle of $45^{\circ}$. It can achieve the flowrate of $5.39 \mathrm{ml} . \mathrm{min}^{-1}$ and the maximum back pressure of $2.82 \mathrm{kPa}$ when the driving voltage is $300 \mathrm{Vp}$-p and the frequency is $25 \mathrm{~Hz}$. The flowrate and the maximum back pressure increase with the driving voltage, however, an overlarge voltage should be avoided for it able to produce the appearance of bubbles in the chamber, leading to a decline of the performance. It suggests that the maximum voltage should not be over $300 \mathrm{~V}$ p-p according to the experimental observation. The optimal driving frequency for this type of micropumps is about $25 \mathrm{~Hz}$ for where the best performance can be obtained with different voltages applied.

A numerical simulation was done to study the working progress, the effect of the diffuser angle as well as the 


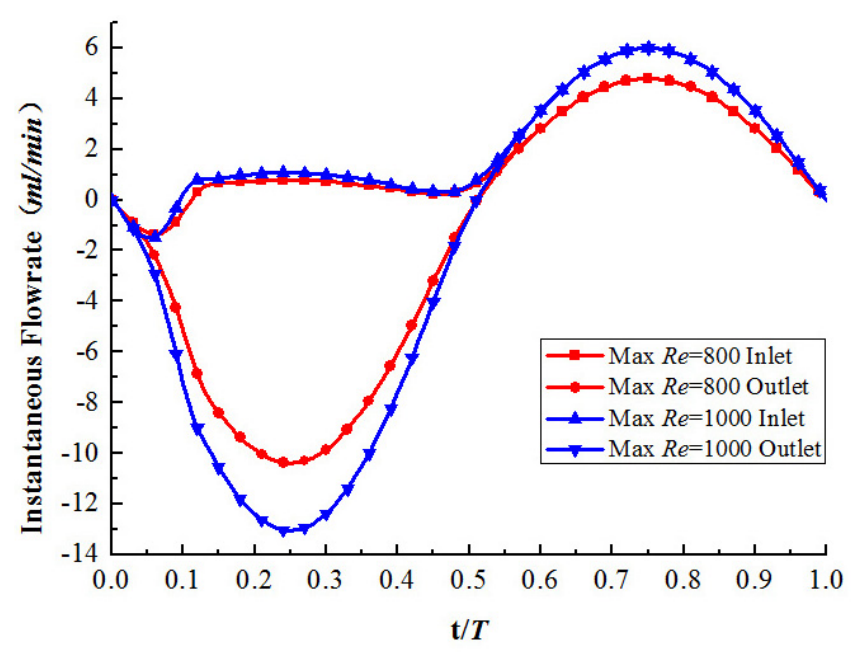

Fig. 18. Instantaneous flowrate through the inlet and the outlet $\left(f=10 \mathrm{~Hz}, \theta=30^{\circ}, R e_{\max }=800\right.$ and 1000).

wall-attached jet on the performance of the micropump. The results obtained by the numerical simulation were compared with that of the experiment with a flowrate deviation of $24 \%$. The findings through the numerical simulation suggest that the suitable range of the diffuser angle is about from $30^{\circ}$ to $45^{\circ}$ where the flowrate and the volumetric efficiency are large and high. As $R e_{\max }$ increases from 200 to 600 , the Coanda effect becomes stronger, resulting in a significant improvement of the volumetric efficiency. As $R e_{\max }>600$, the entrained flowrate appears and contributes to a over $50 \%$ volumetric efficiency. But the entrained flowrate doesn't increase much as $R e_{\max }$ is over 800 .

Acknowledgements. This work was supported by the project of the National Natural Science Foundation of China [grant number: 51276082], Departments of Education and Finance, Jiangsu Province of P.R. China (A Project Funded by the Priority Academic Program Development of Jiangsu Higher Education institutions, PAPD) (Grant No. SUZHENGBANFA (2014) No. 37).

\section{References}

[1] E. Verpoorte, Microfluidic Chips for Clinical and Forensic Analysis, Electrophoresis 23 (2002) 677-712

[2] P. Dario, N. Croce, M.C. Carrozza, G. Varallo, A Fluid Handling System for a Chemical Microanalyzer, J. Micromech. Microeng. 6 (1996) 95-98

[3] E.M.J. Verpoorte, B.H. Van Der Schoot, S. Jeanneret, A. Manz, H.M. Widmer, N.F. De Rooij, Three-dimensional micro flow manifolds for miniatured chemical analysis systems, J. Micromech. Microeng. 4 (1994) 246-256

[4] P.A. Auroux, D. Iossifidis, D.R. Reyes, A. Manz, Micro Total Analysis Systems.2.Analytical standard operations and applications, Anal. Chem. 74 (2002) 2637-2652

[5] P.A. Auroux, D. Iossifidis, D.R. Reyes, A. Manz, Micro total analysis systems.1. Introduction, theory, and technology, Anal. Chem. 74 (2002) 2623-2636
[6] V. Singhal, S.V. Garimella, A. Raman, Microscale pumping technologies for microchannel cooling systems, BIRCK and NCN publications 57 (2004) 191-221

[7] S.L. Zeng, C.H. Chen, J.C. Mikkelsen Jr, J.G. Santiago, Fabrication and characterization of electroosmotic micropumps, Sensors Act. B 79 (2001) 107-114

[8] V.L. Asuncion, P.L. Abraham, An AC magnetohydro dynamic micropump, Sensors Act. B 63 (2000) 178-185

[9] F. Mugele, J. Baret, Electrowetting: from basics to applications, J. Phys.: Condens. Matter 17 (2005) 705-774

[10] P. Gravesen, J. Braebjerg, O.S. Jensen, Microfluidics - a Rev. J. Micromech. Microeng. 3 (1993) 168-182

[11] J. Dopper, M. Clemens, W. Ehrfeld, S. Jung, K. Kamper, H. Lehr, Micro gear pumps for dosing of viscous fluids, J. Micromech. Microeng. 7 (1997) 230-232

[12] A. Hatch, A.E. Kamholz, G. Holman, P. Yager, K.F. Bohringer, A ferrofluidic magnetic micropump, Microelectromech. System 10 (2001) 215-221

[13] R. Wiederkehr, M. Salvadori, J. Brugger, F. Degasperi, M. Cattani, The gas flowrate increase obtained by an oscillating piezoelectric actuator on a micronozzle, Sensors Act. A 144 (2008) 154-160

[14] J. Dopper, M. Clemens, W. Ehrfeld, S. Jung, K. Kamper, H. Lehr, Micro gear pumps for dosing of viscous fluids, J. Micromech. Microeng. 7 (1997) 230-232

[15] C. Yamahata, M. Chastellain, V. Parashar, A. Petri, H. Hofmann, M. Gijs, Plastic micropump with ferrofluidic actuation, Microelectromech. System 14 (2005) 94-102

[16] A. Olsson, G. Stemme, E. Stemme, A valve-less planar fluid pump with two pump chambers, Sensors Act. A 47 (1995) 549-556

[17] A. Olsson, P. Enoksson, G. Stemme, E. Stemme, Micromachined flat-walled valveless diffuser pumps, Microelectromech. System 6 (1997) 161-166

[18] E. Stemme, G. Stemme, A valveless diffuser/nozzle based fluid pump, Sensors Act. A 39 (1993) 159-167

[19] T. Gerlach, H. Wurmus, Working principle and performance of the dynamic micropump, Sensors Act. A 50 (1995) 135-140

[20] F.K. Forster, R.L. Bardell, M.A. Afromowitz, N.R. Sharma, Design fabrication and testing of fixed-valve micro-pumps, Proc. ASME Fluids Eng. Division 234 (1995) 39-44

[21] I. Izzo, D. Accoto, A. Menciassi, L. Schmitt, P. Dario, Modeling and experimental validation of a piezoelectric micropump with novel no-moving-part valves, Sensors Act A 133 (2007) 128-140

[22] A. Fadl, S. Demming, Z. Zhang, S. Büttgenbach, M. Krafczyk, D.M. L. Meyer, A multifunction and bidirectional valve-less rectification micropump based on bifurcation geometry, Microfluidics and Nanofluidics 9 (2010) $267-280$

[23] Z. Deng, X. He, S. Yang, F. Li, Orthogonal optimization design and experiment of oval composite tube in valveless piezoelectric Pump, Trans. Chinese Society Agricul. Mach. 44 (2013) 284-288 
[24] S. Yuan, S. Yang, X. He, Z. Deng, S. Cai, Design and experimental study of a novel three-way diffuser/nozzle elements employed in valveless piezoelectric micropumps, J. Brazilian Soc. Mech. Sci. Eng. DOI: 10.1007/s40430-014-0176-5

[25] D.S. Lee, H.C. Yoon, J.S. Ko, Fabrication and characterization of a bidirectional valveless peristaltic micropump and its application to a flow-type immunoanalysis, Sensors Act. B 103 (2004) 409-415

[26] J.P. Choi, K.S. Kim, Y.H. Seo, B.H. Kim, Design and fabrication of synthetic Air-Jet Micropump, Int. J. Precision Eng. Manuf. 12 (2011) 355-360

[27] Y. Choe, E.S. Kim, Valveless micropump driven by acoustic streaming, J. Micromecha. Microeng. 23 (2013) 45005-45012
[28] K.S. Yang, I.Y. Chen, K.H. Chien, C.C. Wang, A numerical study of the nozzle/diffuser micropump, J. Mech. Eng. Sci. 222 (2008) 525-533

[29] D.J. Tritton, Physical Fluid Dynamics, Van Nostrand Reinhold, Canada, 1977

[30] U. Gebhard, H. Hein, E. Just, P. Ruther, Combination of a fluidic microoscillator and micro-actuator in LIGA technique for medical application, International Conference on Solid State Sensors and Actuators 2 (1997) 761-764

[31] M.K. Jeon, J.H. Kim, J. Noh, S.H. Kim, H.G. Park, S.I. Woo, Design and characterization of a passive recycle micromixer, J. Micromech. Microeng. 15 (2005) 346-351 